\title{
Shift-changes for consultation services affect patient length-of-stay in the emergency department
}

\author{
Sagar Shah, Soheil Saadat, Jennifer Roh \\ Department of Emergency Medicine, University of California, Irvine School of Medicine, Orange, CA 92868, USA \\ Contributions: (I) Conception and design: All authors; (II) Administrative support: None; (III) Provision of study materials or patients: None; (IV) \\ Collection and assembly of data: None; (V) Data analysis and interpretation: All authors; (VI) Manuscript writing: All authors; (VII) Final approval of \\ manuscript: All authors. \\ Correspondence to: Jennifer Roh, MD. Assistant Professor, UC Irvine School of Medicine, Associate Medical Director and Director of Quality \\ Improvement, Department of Emergency Medicine, University of California, Irvine, 333 City Blvd West Suite 600, Orange, CA 92868, USA. \\ Email: jsroh@uci.edu.
}

\begin{abstract}
Increased length-of-stay (LOS) within emergency departments (EDs) is a multifactorial issue that poses additional health risk to patients who chose to leave prior to seeing a physician and also places significant additional burden on ED physicians. Amongst many other patient-related and infrastructural factors, consultation service delay has been deemed a significant contributor to ED LOS across several international studies. We sought to further our understanding of infrastructural factors that contribute to consultation service delay and ED LOS by exploring the effect of shift-changes and patient handoffs. We conducted a retrospective descriptive study of patients receiving consultations in the UC Irvine Medical Center Emergency Department to assess differences in Consultation Duration during timeperiods encompassing a shift change for the consultation service. The two 3-hour intervals with the lowest proportion of acceptable consultation durations (set as 120 minutes) encompassed shift changes and it was not attributable to high workload. Our results serve as preliminary evidence for the need for improved staffing during shift-changes or new shift-change policies to support consultation services during these times. This data also suggests that predictive models built to support operational and administrative decision making in the ED should incorporate shift-change periods and staffing during these times.
\end{abstract}

Keywords: Emergency department (ED); length-of-stay (LOS); consultation; shift-change

Received: 19 March 2020; Accepted: 18 June 2020; Published: 25 September 2020.

doi: $10.21037 /$ jhmhp-20-39

View this article at: http://dx.doi.org/10.21037/jhmhp-20-39

\section{Introduction}

Increased length-of-stay (LOS) within emergency departments (EDs) is a multifactorial issue that poses additional health risk to patients who chose to leave prior to seeing a physician $(1,2)$ while also placing significant additional burden on ED physicians (3). The introduction of the electronic health record (EHR) has augmented our ability to analyze at scale which factors significantly affect LOS and thereby support evidence-based decision making in the sphere of hospital and operations management. Given patient flow through acute care settings is linked to health outcomes, there exists a significant body of literature studying various factors affecting ED throughput, ranging from hospital occupancy and staffing to laboratory and imaging services. A survey study conducted in EDs in the Netherlands found that the most commonly cited perceived contributor to increased LOS was "Consultation Delays" (4), a finding corroborated by several other international studies $(5,6)$. In an attempt to quantify the contribution to LOS, Brick et al. conducted a prospective cohort study of patients requiring consultation services in two urban, Canadian EDs. Consultation duration was found to account for $33 \%$ of LOS for admitted patients and 54\% for discharged 
patients. In cases of 'consultation delay', the study found that the most common reason for the delay was a 'busy service' (47 of 170 delays, 27.6\%) (7). We wished to further our understanding of infrastructural factors that contribute to consultation service delay (and, therefore, ED LOS) by exploring the effect of shift-changes and patient handoffs. We aimed to assess whether handoff periods on one consultation service at the UC Irvine Medical Center were associated with changes in time-to-evaluation by consulting service ("consultation duration"), one of the intervals that total LOS is comprised of. As with other research in this area, the goal of our analysis was not to claim that a given specialty consultation prolonged LOS, but rather to elucidate areas worthy of further consideration.

\section{Methods}

\section{Study population}

Electronic medical records for 577 consecutive ED visits requiring consultation by the chosen service between July 2018 and October 2018 at the UC Irvine Medical Center were obtained from the institutional EHR. All chart review was performed manually by investigators. Only consult calls (CC) for patients aged 18-65 were included. CCs were excluded if laboratory studies besides urine toxicology and pregnancy tests were obtained, if imaging studies were obtained, or if e-meds for sedation were administered for the patient. CCs were also excluded if medical complications precluded immediate evaluation by the consulting service. Additionally, to be included in the analysis, emergency physician notes had to include a specific entry for (I) the time at which consultation services were initially requested and (II) when the consultation service produced a disposition decision.

\section{Data analysis}

Consultation Duration (CD) was defined as the time elapsed from the consulting service being called and the consulting service providing a disposition decision. For each case, CD was deemed either to be of acceptable ( $\leq 120$ minutes) or unacceptable ( $>120$ minutes) duration.

CCs were sorted into 3-hour intervals based on the time at which consultation was placed. For each interval, the median. CD as well as the proportion of consultations completed within 120 minutes was calculated. CD was compared among different time periods by using Kruskal-
Wallis $\mathrm{H}$ test. Each interval was also compared to the 6 am to 9 am period using Mann-Whitney $\mathrm{U}$ test.

\section{Results}

The average CD for the 78 cases included in the analysis was 197.8 (SD: 165.4, range: $23-1,260$, median: $178)$ minutes. The $C D$ varied among different time intervals $(\mathrm{P}=0.047)$ (Figure 1) with highest duration for consults called between 6 am and 9 am $(\mathrm{P}=0.002)$ (Figure 1).

The percentage of consults completed within 120 minutes was lowest ( $0 \%)$ during the 6 am to 9 am time period and the second lowest during the $6 \mathrm{pm}$ to $9 \mathrm{pm}(14.3 \%)$ period (Figure 2). This pattern was not in accordance of consultation workload at the relevant time periods (Figure 3). Both time periods encompassed a shift change of consulting service,

\section{Discussion}

Our preliminary results demonstrate a trend towards increased LOS in the ED for patients requiring consultation services during hand-off periods. During the morning shift-change window, no consultations called occurred in under 2 hours. The evening shift-change window had the second lowest proportion of consultations completed in an acceptable duration. Notably, unlike the other two shift changes, the afternoon shift-change had a relatively higher rate of consultations completed under 120 minutes. Importantly, there is no concurrent increase in workload (as measured by number of consults called) during the window periods that could confound the trends noted in LOS at these times. Though our results were not statistically significant, many aspects of the shift change period could conceivably contribute to our findings. The hand-off period in and of itself may preclude the on-coming consultant from responding to consultation requests while out-going team signs-off to them. Furthermore, responding to requests from primary teams, nursing staff, and patients requires that the new consulting physicians review charts and records of all patients already on the service while also responding to new consultation requests. Furthermore, if the number of team members changes between shifts, the number of patients carried by any one of the physicians may increase, significantly changing indices of 'consultation service burden' without necessarily changing the number of patients on the service. This, in fact, could explain why the afternoon shift-change window did not have a prolonged 


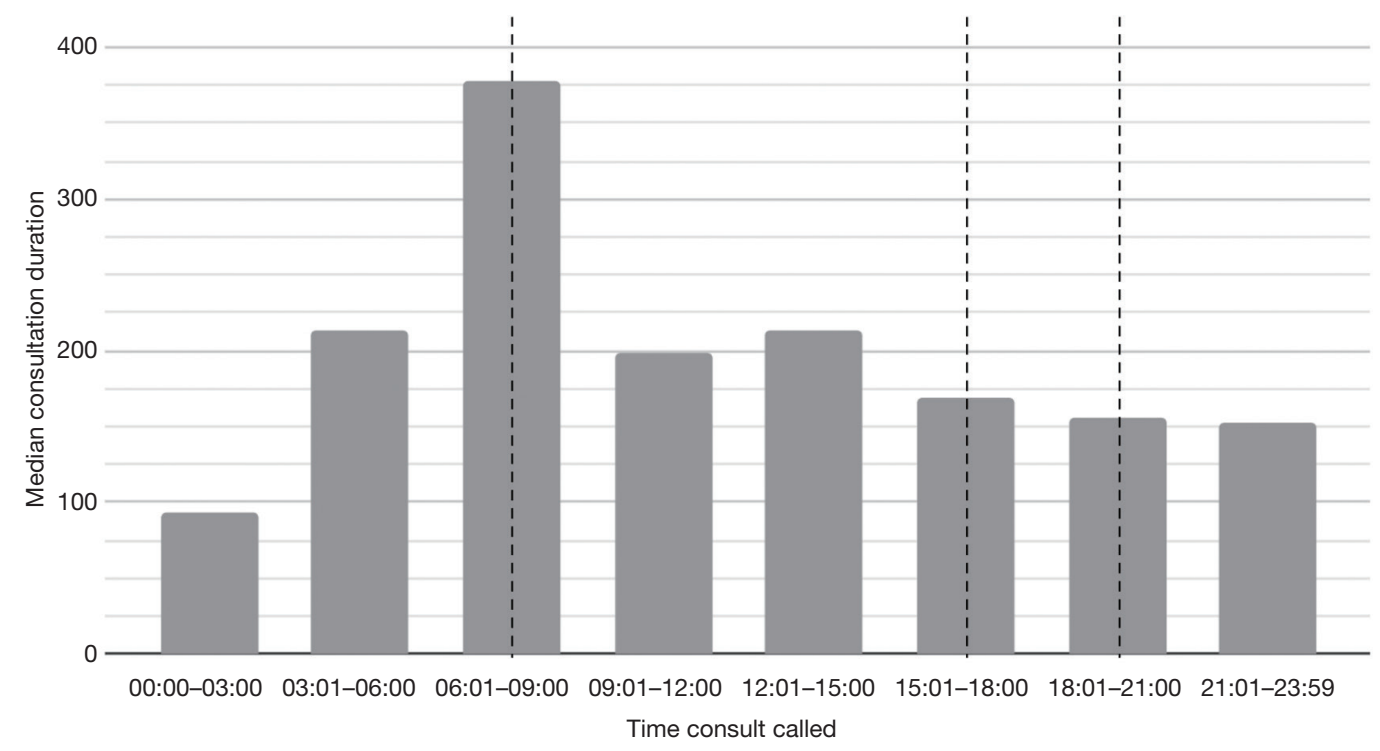

Figure 1 Median duration of consultations called for each three-hour interval with dotted lines representing shift changes.

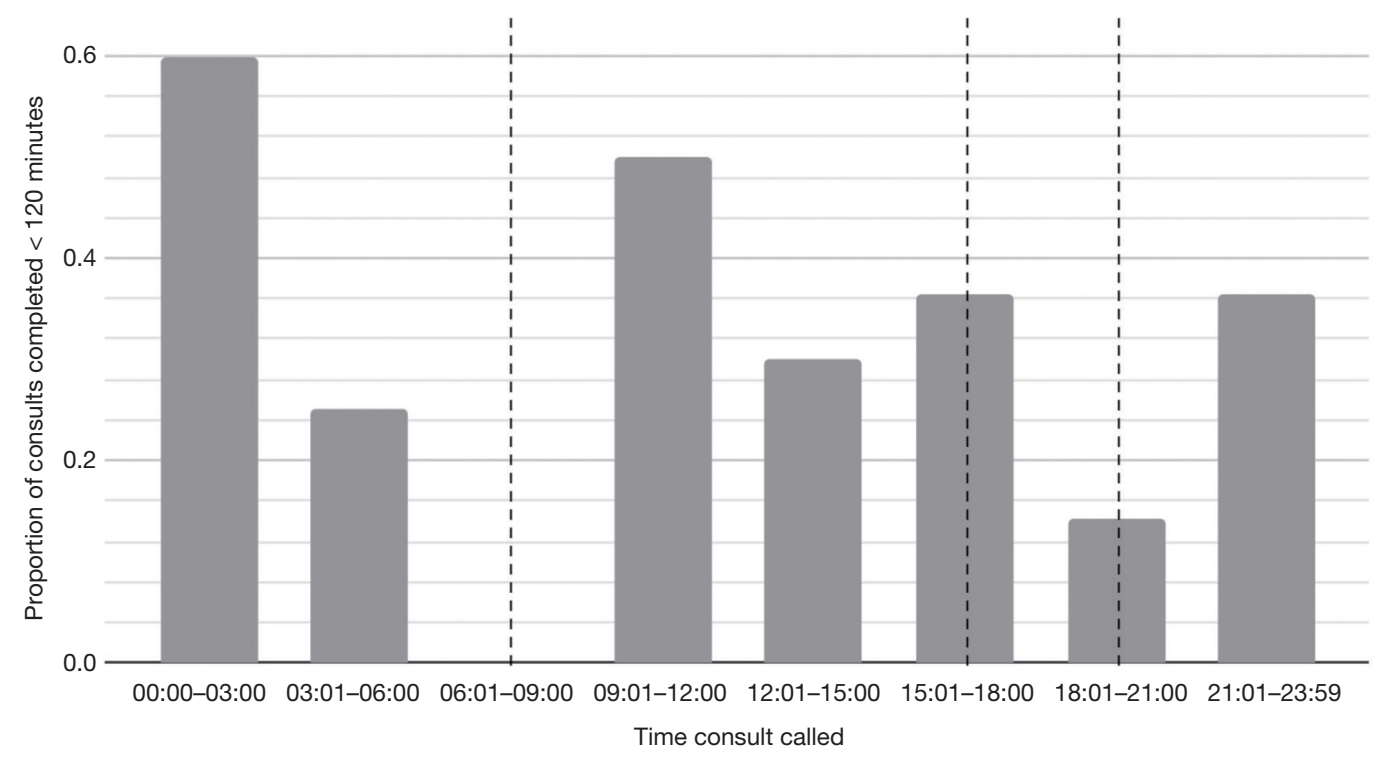

Figure 2 Fraction of consults completed in less than 2 hours for each three-hour interval with dotted lines representing shift changes.

consultation duration like the two other windows; more residents stayed on the service during the afternoon than during the evening. On the service studied in our study, a single night float resident would cover overnight consults while also managing the all patients accumulated on the service by two residents and a fellow in the prior day.

Limitations of our study include a small sample size, a result of a relatively strict inclusion criteria intended to isolate the contribution of shift changes to consultation time and reliance on manual chart review. Furthermore, we studied a single consultation service at an academic institution; further research is necessary to understand whether similar effects of shift-changes exist on other services. Differing staffing models between services may produce differing associations between shift-changes and consultation durations, which would be of interest to investigators building models predicting ED LOS.

Given it has been demonstrated that consultation 


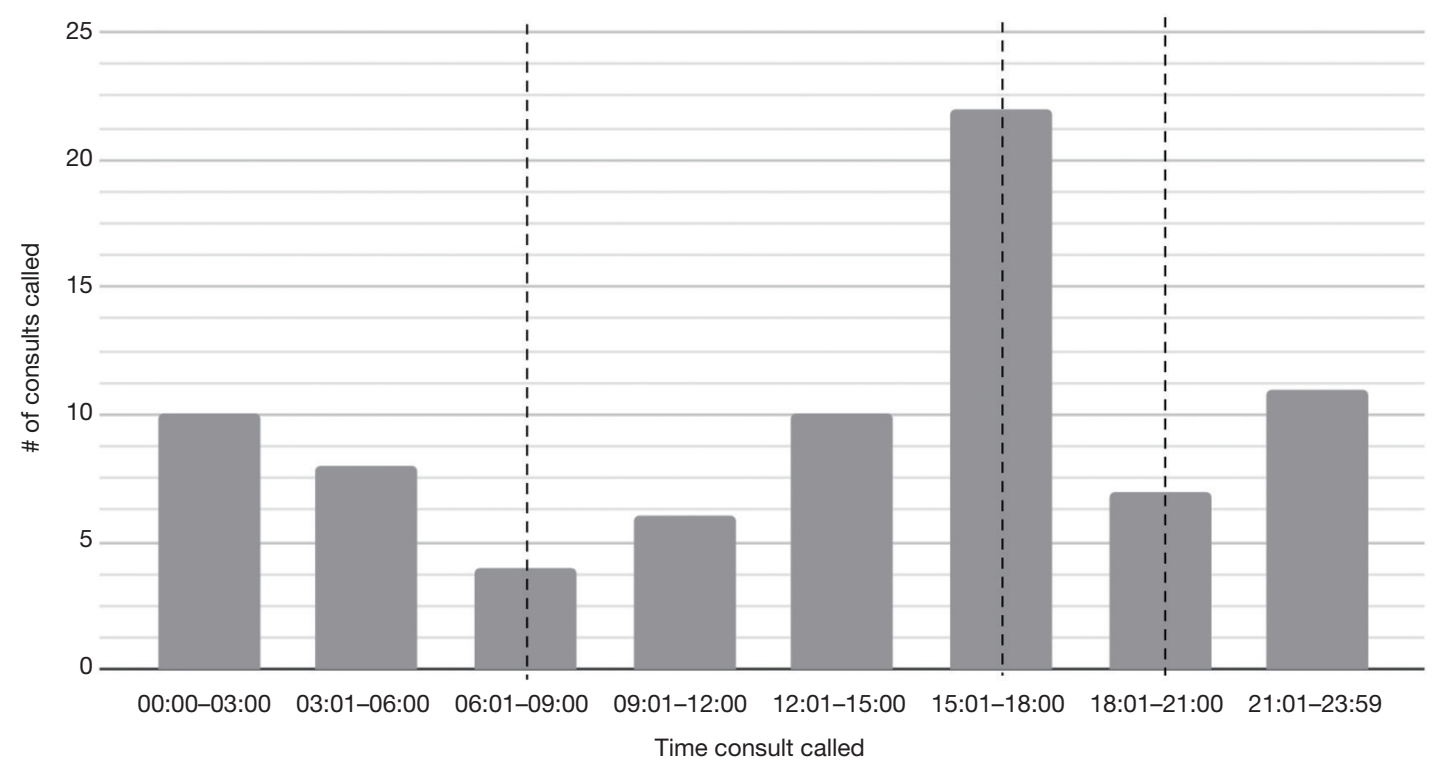

Figure 3 Number of consults called in each three-hour interval with dotted lines representing shift changes.

services play a significant role in determining the LOS for ED patients, our results serve as an initial indication that supports the need for improved staffing during shift changes or new shift change policies to support consultation services during these times. Operations management may benefit from models that predict consultation length and support operational decision making. Based on our initial analysis, we believe such a model would benefit from incorporating shift-change periods into regression analysis.

\section{Acknowledgments}

Funding: None.

\section{Footnote}

Conflicts of Interest: All authors have completed the ICMJE uniform disclosure form (available at http://dx.doi. org/10.21037/jhmhp-20-39). The authors have no conflicts of interest to declare.

Ethical Statement: The authors are accountable for all aspects of the work in ensuring that questions related to the accuracy or integrity of any part of the work are appropriately investigated and resolved.

Open Access Statement: This is an Open Access article distributed in accordance with the Creative Commons Attribution-NonCommercial-NoDerivs 4.0 International License (CC BY-NC-ND 4.0), which permits the noncommercial replication and distribution of the article with the strict proviso that no changes or edits are made and the original work is properly cited (including links to both the formal publication through the relevant DOI and the license). See: https://creativecommons.org/licenses/by-nc-nd/4.0/.

\section{References}

1. Pines JM, Griffey RT. What we have learned from a decade of ED crowding research. Acad Emerg Med 2015;22:985-7.

2. Hoot NR, Aronsky D. Systematic review of emergency department crowding: causes, effects, and solutions. Ann Emerg Med 2008;52:126-36.

3. Asplin BR, Magid DJ, Rhodes KV, et al. A conceptual model of emergency department crowding. Ann Emerg Med 2003;42:173-80.

4. van der Linden C, Reijnen R, Derlet RW, et al. Emergency department crowding in The Netherlands: managers' experiences. Int J Emerg Med 2013;6:41.

5. Mahsanlar Y, Parlak I, Yolcu S, et al. Factors Affecting the Length of Stay of Patients in Emergency Department Observation Units at Teaching and Research Hospitals in Turkey. Turk J Emerg Med 2016;14:3-8. 
6. Derlet RW, Richards JR. Emergency department overcrowding in Florida, New York, and Texas. South Med J 2002;95:846-9.

doi: $10.21037 /$ jhmhp-20-39

Cite this article as: Shah S, Saadat S, Roh J. Shift-changes for consultation services affect patient length-of-stay in the emergency department. J Hosp Manag Health Policy 2020;4:24.
7. Brick C, Lowes J, Lovstrom L, et al. The impact of consultation on length of stay in tertiary care emergency departments. Emerg Med J 2014;31:134-8. 